\title{
Do Corpo-país-invadido ao Corpo-mulher-violada: Nuances da Invasão em Sangria (2017), de Luiza Romão
}

\author{
De lo Cuerpo-pais-invadido a lo Cuerpo-mujer-violada: Matices de la \\ Invasión en Sangría (2017), por Luiza Romão \\ From the Invaded Country to the Violated Woman: Nuances of the \\ Invasion in Sangria (2017), by Luiza Romão
}

\author{
Guilherme Alenício Pires de Souza Medeiros Vieira ${ }^{1}$
}

\begin{abstract}
Resumo
Sangria (2017), de Luiza Romão, estabelece intersecções entre a colonização enquanto invasão das terras e enquanto invasão do corpo feminino. Seus poemas são acompanhados de fotografias em que esses corpos representam o país invadido. A primeira seção é composta por poemas que emulam itens de uma certidão de nascimento. A hipótese é de que, em consonância às categorias de análise levantadas, esses poemas refiram-se mesmo à certidão de nascimento do Brasil enquanto colônia de Portugal. Os outros capítulos desmembram-se em etapas do processo de desenvolvimento de um corpo-mulher associadas a diferentes momentos do processo colonizatório. Os capítulos subsequentes, se lidos conforme a chave de compreensão histórica do processo colonizatório, bem como apoiando no que se sabe acerca da violência de gênero que se perpetua, possibilitam observar a violência contra a mulher no Brasil e associá-la à manutenção dos ideais patriarcais que sobrevivem desde a invasão, em 1500. A proposta, portanto, é, a partir da leitura de seus poemas, destrinchar a colonialidade de modo a abrir caminhos para uma possibilidade de compreensão mais extensa, por exemplo, da situação política do Brasil de 2013 até então, considerando a permanência de uma estrutura colonial adaptada, que reverbera em toda a sistemática política, social, cultural e econômica do Brasil pós-colonial. Fez-se necessário recorrer às considerações de Marilena Chauí (2017) e Lilia Moritz Schwarcz (2019), todos se referindo ao colonialismo e a violência constitutiva do Brasil, além de Jean-Luc Nancy (2015), em relação às possibilidades de desenlace do corpo de prazer.
\end{abstract}

Palavras-chave: Poesia Brasileira Contemporânea; Colonialidade; Necropolítica.

\section{Resumen}

Sangria (2017), de Luiza Romão, establece intersecciones entre la colonización como una invasión de tierras y como una invasión del cuerpo femenino. Sus poemas van acompañados de fotografías en las que estos cuerpos representan el país invadido. La primera sección consiste en poemas que emulan elementos en un certificado de nacimiento. La hipótesis es que, de acuerdo con las categorías de análisis planteadas, estos poemas incluso se refieren al certificado de nacimiento de Brasil como una colonia de Portugal. Los otros capítulos se dividen en etapas del proceso de desarrollo de un cuerpo femenino asociado con diferentes momentos del proceso de colonización. Los capítulos posteriores, si se leen de acuerdo con la clave para la comprensión histórica del proceso de colonización, además de apoyar lo que se sabe sobre la violencia de género perpetua, hacen posible observar la violencia contra las mujeres en Brasil y asociarla con el mantenimiento de los ideales patriarcales. que sobreviven desde la invasión, en 1500. La propuesta, por lo tanto, es, a partir de la lectura de sus poemas, desenredar la colonialidad para abrir caminos para la posibilidad de una comprensión más amplia, por ejemplo, de la situación política de Brasil en 2013 hasta entonces, considerando la permanencia de una estructura colonial adaptada, que reverbera en todo el sistema político, social, cultural y económico del Brasil poscolonial. Era necesario recurrir a las consideraciones de Marilena Chauí (2017) y Lilia Moritz Schwarcz (2019), todas

\footnotetext{
${ }^{1}$ Mestrando em Letras PPGL/UFES - Fapes, Vitória, Espírito Santo, Brazil; guilhermeapsmvieira@gmail.com.
} 
referidas al colonialismo y violencia constitutiva en Brasil, además de Jean-Luc Nancy (2015), en relación con las posibilidades de finalización del cuerpo de placer.

Palabras clave: Poesía brasileña contemporánea; Colonialidad; Necropolítica

\begin{abstract}
Sangria (2017), by Luiza Romão, establishes intersections between colonization as an invasion of lands and as an invasion of the female body. His poems are accompanied by photographs in which these bodies represent the invaded country. The first section consists of poems that emulate items on a birth certificate. The hypothesis is that, in line with the categories of analysis raised, these poems even refer to Brazil's birth certificate as a colony of Portugal. The other chapters are broken down into stages of the development process of a female body associated with different moments of the colonization process. Subsequent chapters, if read according to the key to the historical understanding of the colonization process, as well as supporting what is known about perpetuating gender violence, make it possible to observe violence against women in Brazil and to associate it with the maintenance of patriarchal ideals that survive since the invasion, in 1500. The proposal, therefore, is, from the reading of his poems, to disentangle coloniality in order to open paths for a possibility of a more extensive understanding, for example, of the political situation of Brazil in 2013 until then, considering the permanence of an adapted colonial structure, which reverberates throughout the political, social, cultural and economic system of post-colonial Brazil. It was necessary to resort to the considerations of Marilena Chauí (2017) and Lilia Moritz Schwarcz (2019), all referring to colonialism and constitutive violence in Brazil, besides Jean-Luc Nancy (2015) when it comes to the concept of body of pleasure, a key to understand surviving possibilities.
\end{abstract}

Keywords: Contemporary Brazilian Poetry; Coloniality; Necropolitics.

\title{
1. Ave de rapina que roubou as asas do anjo: enlace e desenlace de um corpo-sem- forma, a um corpo-mulher, atravessada pelo corpo-mulher-violada, munida de um corpo de prazer
}

Luiza Romão é poeta slammer, participa ativamente de batalhas de poesia, nas quais, mais que palavras sob palavras, há corpos vivos, movimento, impulso. Sangria (2017) reúne diversos poemas cujos temas se organizam por data, como num calendário. A começar pela forma do objeto-livro: consonante aos poemas, há fotografias de partes do corpo feminino em preto e branco, com bordados em linha vermelha que poderiam ser submetidas a diversas leituras. A foto que abre o livro é de uma vulva, em cujo centro há um bordado circular, onde foram encaixadas navalhas. Seus poemas parecem ter sido orientados de modo a referirem-se ao processo de constituição de uma identidade.

O primeiro capítulo, Genealogia, apresenta 8 poemas cujos temas se referem a elementos que constituem uma certidão de nascimento. Quem nasce, nos poemas de Luiza Romão, é o Brasil. O Brasil que nasce da invasão, da violência. Quem representa esse país, nas fotografias que acompanham os poemas, é um corpo-mulher. Daí a relação entre os 
termos corpo-país-invadido e corpo-mulher-violada, de modo que sejam conhecidas as conexões propostas por Romão em seus poemas.

Intitulado Descobrimento, o capítulo seguinte é composto por outros 8 poemas, cujos títulos referem-se às primeiras vezes dos eventos que atravessam esse corpo-mulher-violada. O terceiro capítulo, Tensão pré-menstrual, apresenta 5 poemas, que representam sintomas comuns à fisiologia deste corpo. O quarto capítulo, Corte, apresenta 4 poemas com datas de eventos da história recente do corpo-país-invadido, que puderam representar cortes, cisões, rupturas, todas relacionadas ao Golpe de 2016, mas são representados no poema por meio de pílulas, referindo-se ao corpo-mulher-violada. O quinto capítulo, Ovulação, contém um poema que trata do período fértil desse corpo-mulher, análogo ao que a poeta compreende como período fértil do corpo-país, marcado pelos anos 2002-2016, que compõem o título do poema; e o último, Menstruação, contém dois poemas que encerram o ciclo de constituição de identidade desse corpo-mulher-violada em referência ao corpo-país-invadido.

Dentre os poemas, DIA 9. $1^{a}$ MENSTRUAÇÃO parece estabelecer conexões enunciativas que podem determinar a compreensão do controle de um corpo-mulher e da manutenção de sua condição de corpo-mulher-violada. $\mathrm{O}$ poema reflete acerca da primeira menstruação do corpo-mulher-violada a que o texto vem se referindo, e, - considerando a compreensão geral do projeto-livro enquanto vínculo formado entre as representações corpóreas da mulher violada e do país invadido -, faz-se possível buscar a presença destas duas categorias, agora de análise, em todos os poemas.

A menstruação figura na vida da mulher como ponto inicial, na lógica patriarcal, do uso de seus corpos, enquanto via de reprodução. Na linguagem vigente, é "a mulher feita". A menina que "já virou mocinha". A menstruação conota, na ordem do discurso, a possibilidade do uso do corpo da mulher para fins reprodutivos, tanto quando o controle de sua fisiologia por meio de intervenções medicamentosas para controle artificial do aspecto natural do corpo biológico chamado de mulher ${ }^{2}$, o ciclo que controla por si só o funcionamento desse corpo.

Luiza Romão, por meio do eu-lírico, evoca essa imagem do processo de virar mocinha análogo à possibilidade de controle e uso deste corpo-mulher-violada:

$$
\text { quando virei mocinha }
$$

\footnotetext{
2 Importante se atentar para a constituição de outras corporeidades que destoam da lógica biologicista. A exemplo disso: os corpos trans. Este texto não trata desse corpo. Ele trata especificamente do corpo-mulher-cis, de modo que não sejam feitas superinterpretações a partir dos poemas de Luiza Romão, enquanto mulher cis.
} 


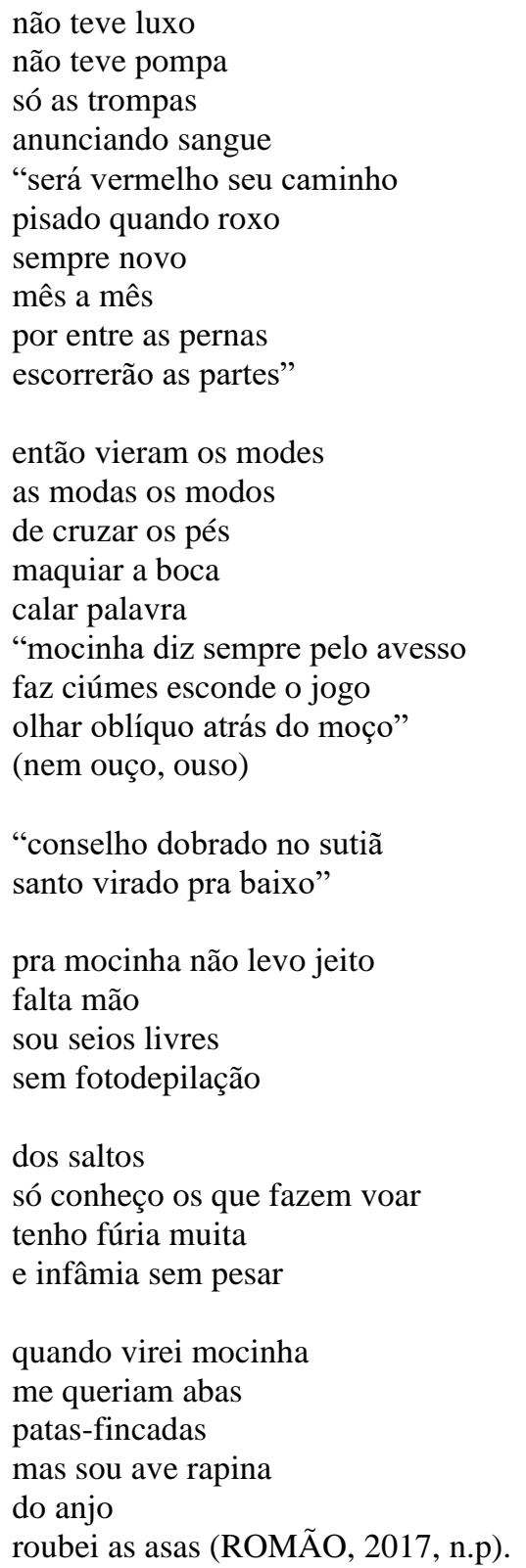

A voz do poema já começa sua asserção utilizando um jargão comum referente à menstruação: virar mocinha. Sobre esse corpo sem-forma que, na menstruação, verte-se em corpo-mulher, incidem determinações que preveem a padronização do corpo, de modo a controlar o que se pode vestir, onde pode habitar, com quem deve casar, com quem deve ter filhos, se deve ou não sentir prazer, o rosto que deve ter. $\mathrm{O}$ corpo-mulher-violada é o corpo invadido pelo discurso vigente patriarcal e europeizado refratário do processo de colonização das terras e dos corpos de origem, processo do qual vêm "os modes/ as modas os modos/ de cruzar os pés/ maquiar a boca/ calar palavra” (ROMÃO, 2017, n.p).

Donna Harraway (1995) compreende ser impossível conceber objetos de ciência sem compreendê-los enquanto corpos viventes, atores, agentes sociais, de modo a não relegá-los 
aos parâmetros cartesianos da ciência, a qual determina referenciais de padrão para a existência desses corpos. A partir de considerações da estudiosa é possível compreender que o sexo permitido ao corpo-mulher-violada é este com fins instrumentais, de recurso: a reprodução, ou de prazer do sujeito violador. Não raro é possível deparar-se com campanhas de comunidades protestantes contra o uso de métodos contraceptivos, por exemplo. O virar mocinha, do poema de Luiza Romão, pode ser o que insere a mulher nessa lógica de instrumentalização do corpo na sociedade patriarcal e capitalista, e nega-lhe a organicidade de seu próprio corpo, conferindo-lhe a condição de recurso.

A ruptura que Romão apresenta no poema é justamente com essa lógica padronizante do corpo da mulher, que já nasce violado. As três primeiras estrofes apresentam o corpomulher-violada com referência na violação da invasão do pensamento ocidental, que reverbera diariamente nos discursos vigentes e na indústria cultural. Das três, a segunda parece dizer respeito ao processo de civilização dessa mulher, que agora moça, deve abandonar a infixidez de seu eu, característico da infância, enquanto origem natural, animalizada, mimética.

Dessa proposta, também faz-se possível uma leitura do corpo-país-invadido, que pressupôs a aculturação dos indígenas e dos povos de África, de modo a inculcar-lhe o padrão de civilização europeu, o que incorre em modos, modas, costumes e outros aspectos culturais. Todos eles reverberam sobre o corpo, de modo a silenciá-los, descorporifica-los e espiritualiza-los à maneira europeia.

Lilia Schwarcz, em seu recente livro Sobre o autoritarismo brasileiro (2019) tece um panorama geral das reminiscências do processo de invasão europeia para colonização das terras e dos corpos, via diversos tipos de violência, tais quais a aculturação, o etnocídio, o estupro, etc. A pesquisadora assevera que estão presentes, no substrato social brasileiro, reverberações desse processo, que agem como forma de manutenção dos paradigmas de poder. Dentre os assuntos sobre os quais disserta, está a violência de gênero.

Conforme explicita,

Mulheres correspondem a 89\% das vítimas de violência sexual no Brasil. Entre 2001 e 2011, 50 mil mulheres foram assassinadas, de acordo com dados do Instituto de Pesquisa Econômica Aplicada (Ipea). Mesmo assim, o termo 'feminicídio' só foi formalmente reconhecido aqui a partir de março de 2015, tipificando a existência de crimes premeditadamente cometidos contra mulheres (2019, p. 184). 
Além dessa violência, a autora afirma haver outros perigos às mulheres: a falta de acessibilidade ao direito constitucional à saúde, bem como a busca por clínicas clandestinas de aborto - em geral, provocados, vitimam diariamente cinco mulheres por complicações em partos e quatro por aborto (SCHWARCZ, 2019).

A autora propõe que "[...] a única maneira de enfrentar a violência de gênero é atuar com políticas públicas estruturadas que envolvam diversas dimensões, como o trabalho, a família, a saúde, a renda, a igualdade racial e de oportunidades" (SCHWARCZ, 2019, p. 186). Em todas essas estruturas, há a perpetuação de ideais refratários do processo de colonização, em vista de sua perpetuação, pela falta de enfrentamento de “[...] valores paternalistas, machistas e heteronormativos predominantes e intocados no decorrer da sua história" (SCHWARCZ, 2019, p. 185). Lilia Schwarcz lembra ainda da "cultura do estupro", sobre a qual afirma que "O início dessa história está vinculado ao projeto colonial, cujo funcionamento pautou-se no uso alargado de mão de obra escrava e compulsória: indígena e/ou africana" (2019, p. 190).

Em contrapartida às primeiras estrofes do poema, as três outras apresentam o rompimento do eu-lírico com essa lógica. É nelas que o eu-lírico diz de si mesma: "pra mocinha não levo jeito/ falta mão/ sou seios livres/ sem fotodepilação// dos saltos/ só conheço os que fazem voar/ tenho fúria muita/ e infâmia sem pesar" (ROMÃO, 2017, n.p). É o corpomulher-violada que se vê enquanto potência de ruptura, rompendo com as lógicas patriarcais e capitalistas de existência.

Acerca dessa outra percepção de si, pós-ruptura com o discurso vigente, Jean-Luc Nancy asserta no capítulo Corpo de prazer, de seu livro Corpo, fora (2015), que

(O corpo de prazer) é um corpo liberado de seus esquemas perceptivo e operatório, que não mais se dá a ver e nem sentir em geral, segundo as modalidades de sua vida funcional, ativa ou relacional. É o corpo que não está mais voltado para o mundo e nem mesmo para o outro com o qual - tratando-se do prazer sexual - estabelece uma troca (NANCY, 2015, p. 25, grifo do autor).

O eu-lírico, no poema em questão, parece refletir justamente acerca dessa ruptura com o uso funcional do corpo-mulher-violada com fins de reprodução. Pode ser que essa ruptura seja a potência geradora do corpo de prazer, que

é o corpo enquanto capacidade de se transformar, de se reformar ou, querendo-se, de se in-formar (ou bem de se exformar...) - passando de uma conformação, diga-se de uma conformidade regulada por um conjunto de práticas sociais, culturais, técnicas a uma forma ela mesma tendendo a uma formação incessante (NANCY, 2015, p. 26). 
Ocorre uma passagem de um corpo-mulher-violada para um corpo de prazer, autorreferente, que se propõe a transformações, reformas, o corpo do devir, rompido com a estagnação determinista patriarcal que impõe à mulher a condição de corpo-mulher-violada, e é em função dessa passagem que o eu-lírico se põe ave de rapina, se projeta em outra corporeidade, agrega a si seus componentes de sobrevivência, sua garra, sua visão aguçada, sua rapidez e sua sensualidade, traduzida na assertividade de seus golpes. Romão parece propor que o enlace da subjetividade do corpo-mulher-violada pode ser desfeito e refeito se for desempenhado esse corte entre a condição a que foi relegada e a sua corporeidade natural, orgânica, animalesca, ave de rapina.

Gabriel Giorgi compreende que, em decorrência da inserção do animal na cultura e dos novos modos de relação entre seres humanos e animais,

[...] o animal começa a funcionar de modos cada vez mais explícitos como um signo político. Muda de lugar nas gramáticas da cultura e ao fazê-lo ilumina políticas que inscrevem e classificam corpos sobre ordenamentos hierárquicos e economias da vida e da morte - isto é: os ordenamentos biopolíticos que "produzem" corpos e lhes atribuem lugares e sentidos num mapa social (GIORGI, 2016, p. 10).

Quando o eu-lírico de Romão nega a condição de "patas-fincadas", evoca uma corporeidade outra e atribui-lhe características negativas. Dos quadrúpedes, patas-fincadas, o progresso e a técnica fizeram uso constante. A esses corpos foi relegada a condição de instrumento de carga, utilizado como força motriz em moinhos e outros objetos tecnológicos, além de alimento. Esse corpo, análogo ao corpo-mulher-violada, é o que está inscrito na biopolítica como corpo a ser disciplinado, controlado, utilizado, objetificado, vendido, comprado. A biopolítica prescreve, portanto, os corpos tomados para objeto, sobre os quais se inscrevem modos de vida e de preservação da vida, com fins de manutenção da norma vigente, patriarcal e capitalista, bem como o empurrar para a morte característico dessa mesma norma.

O autor ainda propõe que

[...] o que faz com que o animal perca de sua natureza figurativa e de sua definição formal, e se torne antes uma linha de desfiguração: menos a instância de uma forma reconhecível, de um corpo diferenciado e formado, que um umbral de indistinção, um corpo de contornos difusos e que conjuga linhas de intensidade, de afeto, de desejo que não se reduzem a uma, por assim dizer, "forma-corpo". Menos, pois, a instância de "representação" que a de uma captura de forças, o animal nestes textos parece exceder e eludir toda figuração estável - transformando-se numa instância que, a partir da corporalidade mesma, protesta contra toda figuração, forma, representação, e reclama modulações e registros estéticos que permitam captar e codificar isso singular que passa entre os corpos e que resiste a toda classificação e a todo lugar predefinido. Trata-se, então, de pensar os modos como o animal 
transforma as lógicas de sua inscrição na cultura e nas linguagens estéticas, interrogando, ao mesmo tempo, uma reordenação mais ampla de corpos e de linguagens da qual essa nova proximidade do animal dá testemunho (GIORGI, 2016, p. 30-31).

Romão, ao evocar a imagem da ave rapina, em oposição ao animal de patas-fincadas, mobiliza justamente essas linhas de intensidade que são negadas ao corpo-mulher-violada, excedendo as fronteiras dessa representação modulada pela ordem do discurso e se permitindo habitar o espaço do comum, em que a partilha e a troca de experiências beneficiam a constante deformação e reformação, ambas propostas por Nancy.

A imagem da ave rapina que dos anjos roubou as asas estabelece a relação entre esses dois corpos viventes. Para o eu-lírico, nada de patas-fincadas, mas voo alto e livre de ave de rapina. O eu-lírico parece capturar a força - nas palavras de Giorgi - dessa inscrição animal na cultura, a fim de mobilizar suas estratégias de sobrevivência e desamarrar-se das condições a que foi relegada enquanto corpo-mulher-violada.

A possibilidade de sobrevivência à ordem vigente, conforme parecem elucidar Luiza Romão, Donna Harraway, Jean-Luc Nancy e Gabriel Giorgi, portanto, está no processo de reinscrição dos corpos viventes no discurso, de modo que, pela diferença, atribuam-se de percepções outras que refiram-se às corporalidades cuja condição é análoga à sua.

Levados ao extremo do espaço de enunciação, compreender esses corpos sobreviventes poderia, à minha perspectiva, configurar uma possibilidade de entrever a subjetividade coletiva por meio das frestas da biopolítica. A saída, talvez, para a corporificação e atenção à organicidade do corpo estaria na escuta às outras corporeidades dissonantes, categorias de alteridade surgidas conforme o desenrolar das castrações sociais; e o que tem-se a ouvir de corpos-mulheres-violadas são seus modos de sobrevivência à soberania das relações sociais enraizadas na colonialidade, no patriarcalismo e no capitalismo, de modo a romper com sua lógica de invasão.

\section{Referências}

GIORGI, Gabriel. Formas comuns: animalidade, literatura, biopolítica. Trad. Carlos Nougué. Rio de Janeiro: Rocco, 2015.

HARAWAY, Donna. Ciencia, cyborgs y mujeres. La reinvención de la naturaleza. Trad, Manuel Talens. Madri: Ediciones Cátedra, 1995. 
ROMÃO, Luiza. Sangria. São Paulo: Selo do Burro,2017.

SCHWARCZ, Lilia Moritz. Sobre o autoritarismo brasileiro. São Paulo: Cia. das Letras, 2019.

NANCY, Jean-Luc. Corpo, fora. Trad. e org. Márcia Sá Cavalcante Schuback. Rio de Janeiro: 7Letras, 2015. 